\title{
IDENTIFICACIÓN DE HONGOS FITOPATÓGENOS Y PRESENCIA DE SALMONELLA SP EN COMPOST DE PLANTAS DE TRATAMIENTO DE AGUAS RESIDUALES
}

Por:

Ing. Jorge Antonio Silva Leal' ,Ph.D Patricia Torres Lozada², Ph.D Juan Escobar Rivera ${ }^{3}$

\section{RESUMEN}

Este estudio presenta las metodologías adaptadas para identificación de hongos fitopatógenos (Botrytis sp, Fusarium sp., Phytophthora sp., Rhizoctonia sp) y Salmonella sp. Se evaluó la presencia de fitopatógenos y Salmonella sp en compost producido a partir de lodo primario espesado y deshidratado-LED generado en la Planta de Tratamiento de Aguas Residuales de Cañaveralejo-PTAR-C-Cali. La adaptación de las metodologías mostró que las diluciones adecuadas para el aislamiento de hongos fitopatógenos en las muestras de compost son 10-3, 10-4, 10-5 y el medio de cultivo selectivo más apropiado para la identificación de Salmonella sp fue el agar Salmonella-Shigella. El único fitopatógeno presente en el compost fue Fusarium sp, también se encontró presencia de Salmonella sp. Por lo tanto, se recomienda realizar su cuantificación para definir en qué concentraciones puede llegar a convertirse en un problema de salud pública; adicionalmente, se debe realizar la higienización del compost para su aplicación agrícola principalmente en cultivos industrializados.

Palabras Claves: Compost, Fitopátogenos, Salmonella sp.

\section{ABSTRACT}

This study shows adapted methodologies to identify of phytopathogens fungi (Botrytis spp, Fusarium sp., Phytophthora sp., Rhizoctonia sp) and bacteria as Salmonella sp. Presence of mentioned microorganism was evaluated in compost samples produced from dewatering primary sludge, generated in Cañaverale- jo Wastewater Treatment Plant -WWTPC. The adapted methodologies shown that the appropriate dilutions for isolation of phytopathogens fungi in compost are $10^{-3}$, $10^{-4}$ and $10^{-5}$ and the most appropriated selective culture medium for the salmonella $\mathrm{sp}$ identification is the Salmonella-Shigella agar. Fusarium sp was the only phytopathogens fungi founded in compost; Salmonella sp was also founded. Therefore, it is recommended the quantification in order to define the concentrations that can cause health problems; additionally, it is necessary sanitization of compost for use in agriculture, mainly in industrial crops.

Keywords: Compost, Phytopatogens, Salmonella sp.

\section{INTRODUCCIÓN}

La composición y concentración de los componentes de las aguas residuales domésticas dependen en gran medida de las condiciones socioeconómicas de la población, así como de la presencia del vertimiento de efluentes industriales en la red de alcantarillado; en regiones industrializadas, la fracción de residuos industriales presente en el agua residual doméstica puede ser significativa, alterando las características de los mismos [6].

Las aguas residuales domésticas contienen seis clases principales de contaminantes: organismos patógenos, materia orgánica, sólidos suspendidos, nutrientes, olor, y metales pesados, siendo los organismos patógenos la clase de contaminantes más importante para la salud humana [18]. Para remover los contaminantes presentes en el agua residual, existen Operaciones físicas, Procesos biológicos y Procesos químicos. En la mayoría de los casos es necesario utilizar una combinación de operaciones y procesos para alcanzar la eficiencia de remoción deseada [7].

\footnotetext{
'Ingeniero de Producción Biotecnológica. Universidad Francisco de Paula Santander. jorgesilvaleal@hotmail.com

2Doctora Universidad de Sao Paulo Brasil, Profesora Asociada Universidad del Valle. patoloz@univalle.edu.co

3Doctor Universidad de Sao Paulo Brasil. Jefe de Operación Planta Puerto Mallarino. EMCALI. jcescobar@emcali.com.co
} 
Gran parte de los contaminantes se remueven en forma de sólidos, lodos y biosólidos, los cuales incluyen material grueso de las etapas preliminares y lodos orgánicos e inorgánicos, que deben ser tratados, dispuestos y/o aprovechados. La aplicación de un tratamiento adecuado para los lodos de las Plantas de Tratamiento de Aguas Residuales- PTAR busca resolver los problemas de contaminación, alteración de ecosistemas y desmejoramiento de la calidad de vida del ser humano, derivados de su producción. Adicionalmente, también se pretende generar ahorros significativos a nivel agrícola mediante el aprovechamiento de su potencial nutricional que depende del tipo de tratamiento que se les aplique [7].

La estabilización de la materia orgánica de los lodos de PTAR se puede lograr mediante tecnologías aerobias o anaerobias dentro de las cuales se destacan el compostaje y la lombricultura, que pueden ser viables debido a que este tipo de residuos contiene cantidades significativas de materia orgánica, nutrientes y oligoelementos (N, P, K, Ca, Fe, Mn). Es importante que el lodo presente ausencia o valores bajos de metales pesados para que no se inhiban los procesos biológicos en los que se basan estas tecnologías [19].

El compostaje es el proceso de descomposición biológica de los constituyentes orgánicos de los residuos en el cual intervienen numerosos y variados microorganismos que requieren de una humedad adecuada y sustratos orgánicos heterogéneos en estado sólido que son degradados para obtener al final una materia orgánica estabilizada, libre de fitotoxinas y dispuesta para su empleo en la agricultura sin provocar fenómenos adversos [3].

Desde el punto de vista químico, el compost ofrece grandes beneficios a los suelos debido a que tiene una capacidad de intercambio catiónico $(\mathrm{ClC})$, suministra nitrógeno, potasio y fósforo, aporta oligoelementos como hierro, manganeso, zinc, boro, molibdeno y cobre y contribuyendo a solubilizar algunos elementos minerales del suelo, facilitando su asimi- lación por las plantas. Adicionalmente, la actividad biológica del suelo se ve favorecida por el aporte de bacterias que contribuyen a la descomposición de componentes minerales insolubles [12].

El proceso de compostaje es exotérmico, lo cual implica que en la fermentación aerobia se produce multiplicación significativa de la población microbiana y un incremento acelerado de la temperatura que es importante para la destrucción de patógenos, cuya tasa de mortalidad esta en función de la misma y el tiempo; la mayoría de los patógenos son destruidos rápidamente cuando todas las partes de la pila de compost están sometidas a una temperatura de aproximadamente $55^{\circ} \mathrm{C}$ [16].

Existen algunos hongos que pueden colonizar el compost y que son causantes de las mayores enfermedades en las plantas conocidos como fitopatógenos [5]. Botrytis sp es un hongo capaz de atacar semillas, plántulas, flor, tallo y residuos de cosechas; las condiciones ideales para su desarrollo son alta humedad relativa, agua libre sobre las plantas y temperatura menor a $25^{\circ} \mathrm{C}$. Los síntomas se asemejan bastante a los causados por Rhizoctonia solani [1 1].

El género Fusarium sp se relaciona con enfermedades radiculares y de sistema vascular de muchas especies de plantas. Causan marchitez en varias especies de plantas y afectan algunas gramíneas. Algunas especies de este hongo tienen la capacidad de formar clamidosporas, además de las conidias a través de las cuales se diseminan [2].

Existen varias especies de Phytophthora sp que pueden matar a muchas plantas; viven en el suelo y cuando se dan las condiciones ideales colonizan las raíces y la zona del cuello de las plantas. La causa principal que activa al patógeno es el exceso de agua en el cultivo; su aislamiento se realiza en medio agar avena con una solución stock de antibiótico [9]; [15].

Rhizoctonia sp produce la pudrición de la raíz prin- 


\section{IDENTIFICACIÓN DE HONGOS FITOPATÓGENOS Y PRESENCIA DE SALMONELLA SP EN COMPOST DE PLANTAS DE TRATAMIENTO DE AGUAS RESIDUALES}

cipalmente en plántulas jóvenes, con su posterior muerte. En plantas más maduras se observan lesiones acuosas grises en los pecíolos de la hoja y en las venas centrales cerca del suelo. [11]; [14].

El aislamiento de los hongos Botrytis sp, Fusarium sp, y Rhizoctonia sp se realiza en agar PDA, y la identificación con tinción de las esporas de reproducción y microoscopía.

Otro microorganismo patógeno tanto para los humanos como para los animales es Salmonella sp importante desde el punto de vista de salud pública ya que es el agente causal de varias enfermedades infecciosas como: fiebres entéricas, gastroenteritis, y fiebre tifoidea [1]. La presencia de este patógeno en el compost constituye un riesgo por la supervivencia después de su aplicación en el suelo y la contaminación de los cultivos que entran en contacto directo con él [1].

En el presente estudio se realizó la identificación de los hongos fitopatógenos Botrytis spp, Fusarium sp, Phytophthora sp y Rhizoctonia sp y Salmonella $s p$ en el compost producido con lodo de la Planta de Tratamiento de Aguas Residuales de Cañaveralejo PTAR-C.

\section{MATERIALES Y METODOS}

La investigación se realizó en las instalaciones de la Planta de Tratamiento de Aguas Residuales de Cañaveralejo de la ciudad de Cali; el material evaluado fue obtenido a partir del compostaje aerobio del lodo proveniente de la sedimentación primaria de la PTARC previamente espesado y deshidratado-LED. El estudio se desarrolló en dos etapas, un ensayo preliminar que tuvo como objetivo la adaptación de las técnicas de aislamiento e identificación de hongos fitopatógenos y Salmonella sp y un ensayo final que permitió la identificación de los microorganismos patógenos.

\section{ENSAYO PRELIMINAR}

\section{Análisis de fitopatogenicidad}

El análisis de fitopatogenicidad consistió en el aislamiento microbiológico e identificación de especies relevantes que se encuentran contempladas en la norma ICONTEC NTC 5167 2003, para productos de la industria agrícola y materiales usados como fertilizantes [10] y que establece que los productos orgánicos obtenidos a partir de materiales vegetales deberán garantizar la ausencia de los géneros de hongos fitopatógenos Botrytis spp, Fusarium spp., Phytophthora spp., Rhizoctonia spp

Para la identificación de estos microorganismos se preparó una muestra de compost macerado y se sembró en un medio de cultivo papa dextrosa agar (PDA) para los géneros Fusarium sp [2], Botrytis sp, [8] y Rhizoctonia sp [14] y en agar avena (AA) con una solución stock de antibiótico (penicilina $10 \mathrm{gr} / 20 \mathrm{ml})$ ) para Phytophthora sp [15].

Las diluciones empleadas fueron $10^{-6}, 10^{-7}, 10^{-8}$ usando siembra en superficie. La identificación se realizó después de un periodo de 8 días de incubación a 28 ${ }^{\circ} \mathrm{C}$. Posterior a la identificación se realizó la identificación macróscopica de las colonias crecidas, para purificarlas y llegar a la identificación microscópica. La Figura 1 muestra la metodología utilizada para el aislamiento de hongos fitopatógenos [13]. 
Figura 1. Metodología utilizada para el aislamiento de hongos fitopatógenos en el ensayo preliminar [13]

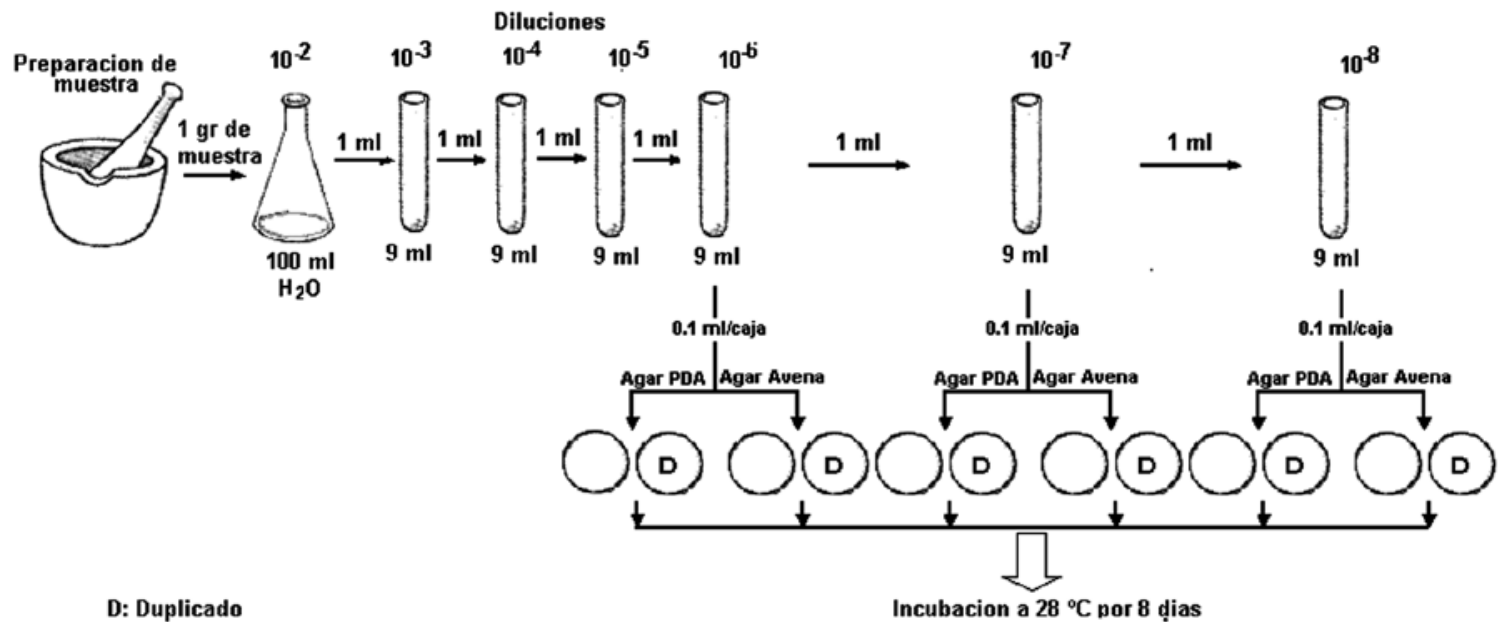

\section{Aislamiento de salmonella sp}

Se realizó un preenriquecimiento en caldo de lactosa a $37^{\circ} \mathrm{C}$ por 48 horas y un posterior enriquecimiento. En la primera fase se evaluaron dos caldos, selenito cistina y tetrationato, adicionando $25 \mathrm{gr}$ de muestra de compost a $225 \mathrm{ml}$ de caldo lactosa y transfiriendo $1 \mathrm{ml}$ de está solución a $10 \mathrm{ml}$ de cada uno de los caldos seleccionados (tres tubos por muestra) y se incubó por un período de 48 horas a $37^{\circ} \mathrm{C}$. (etapa de enriquecimiento) [13].

La siembra en medio selectivos se realizó en superficie por agotamiento en un agar selectivo; para esta fase se utilizaron dos medios de cultivo selectivos: bismuto sulfito (BS) y agar salmonella - shigella (SS) incubándose a $37^{\circ} \mathrm{C}$ por 48 horas con el objetivo de obtener la mejor identificación de Salmonella sp [13].

La identificación de salmonella en el agar BS se logra al observar colonias pardas con el centro negro, borde claro y precipitado negro con brillo metálico. Este medio no permite identificar Salmonella paratyphi A y Salmonella pollorum [8].
La mayoría de Salmonellas no muestran coloración en el agar SS, las colonias transparentes con el centro negro corresponden a proteus y algunas salmonellas [8]. La Figura 2 muestra la metodología empleada para la identificación de Salmonella sp [13].

Figura 2. Metodología de aislamiento de Salmonella sp en el ensayo preliminar [13]

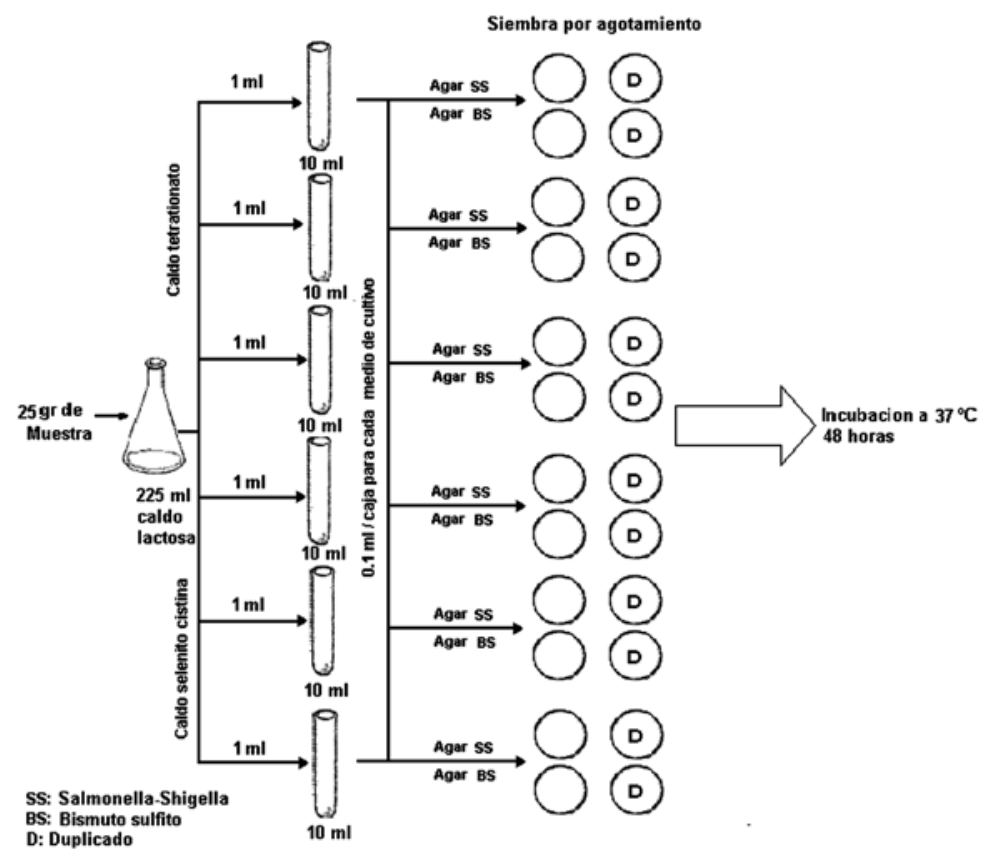




\section{ENSAYO FINAL}

\section{Aislamiento e identificación de hongos fitopató- genos}

Los hongos patógenos se aislaron con base en los resultados obtenidos en el ensayo preliminar durante la estandarización del método de aislamiento, en el cual se definió emplear las diluciones $10^{-3}, 10^{-4} \mathrm{y}$ $10^{-5}$. La Figura 6 muestra la metodología empleada en esta etapa del estudio para el aislamiento de hongos fitopatógenos [13].

Figura 6. Metodología utilizada para el aislamiento de hongos fitopatógenos en el ensayo final [13]
Se realizó una identificación macroscópica por características de crecimiento y color; posteriormente se realizó una identificación microscópica de las esporas de reproducción mediante una tinción simple con azul de lactofenol.

\section{Aislamiento de salmonella sp}

Según los resultados del ensayo preliminar, se decidió emplear para el enriquecimiento el caldo tetrationato que fue el que mejor resultado presentó. La siembra en medio selectivo se realizó en superficie por agotamiento en agar Salmonella-Shigella (SS) ya que permitió una mejor identificación de las colonias.

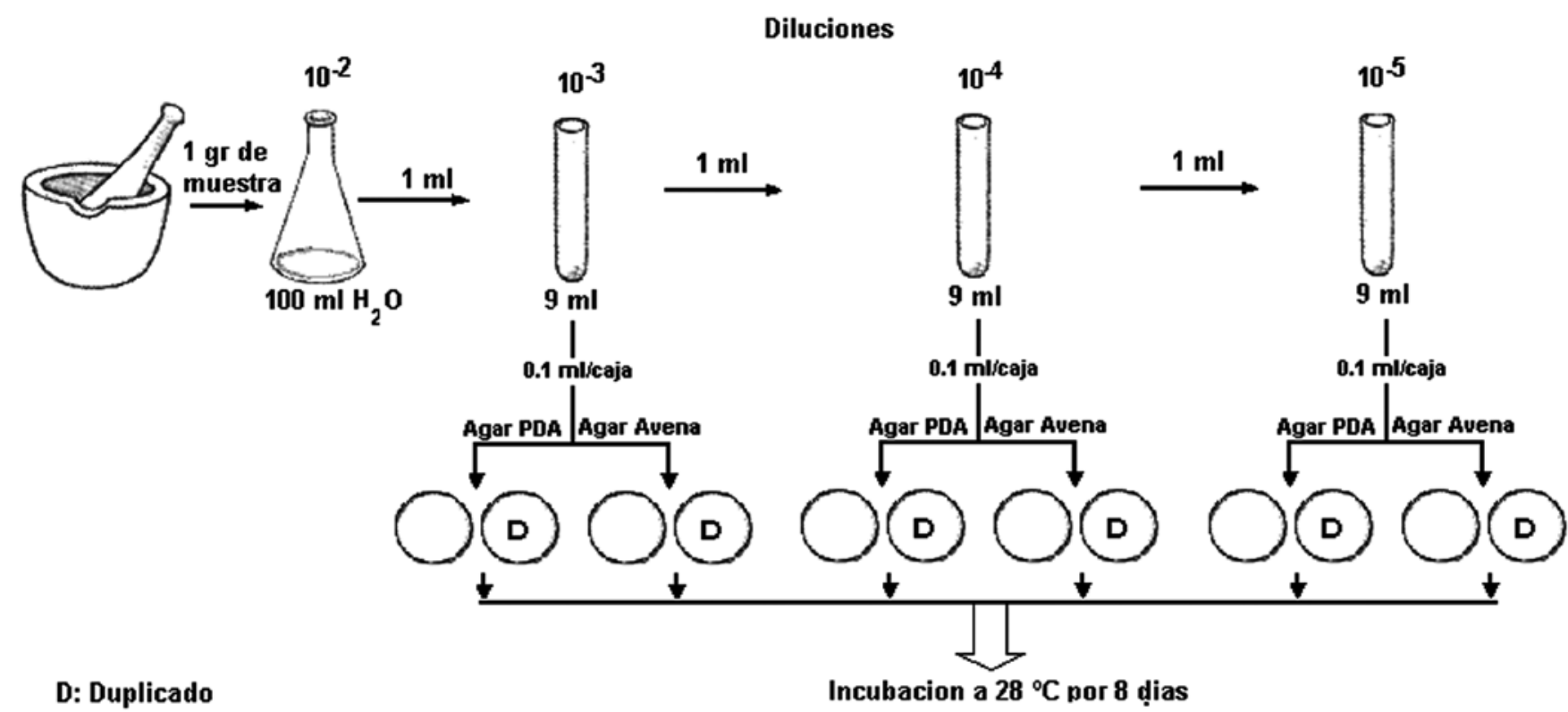

Dado que en este ensayo se utilizaron diluciones bajas, se pudieron aislar algunas colonias para realizarles una purificación del cultivo para su posterior identificación. Una vez aisladas las colonias en los distintos medios, se procedió a la purificación de las mismas realizando tres pases a sus respectivos medios, para la identificación microscópica de las esporas de reproducción.

Se incubó a $37^{\circ} \mathrm{C}$ por 48 horas y la lectura de los resultados se realizó de igual forma que en el ensayo preliminar. La Figura 7 muestra la metodología usada en el aislamiento de Salmonella sp para el ensayo final [13]. 
Figura 7. Metodología de aislamiento de Salmonella sp para el ensayo final [13]

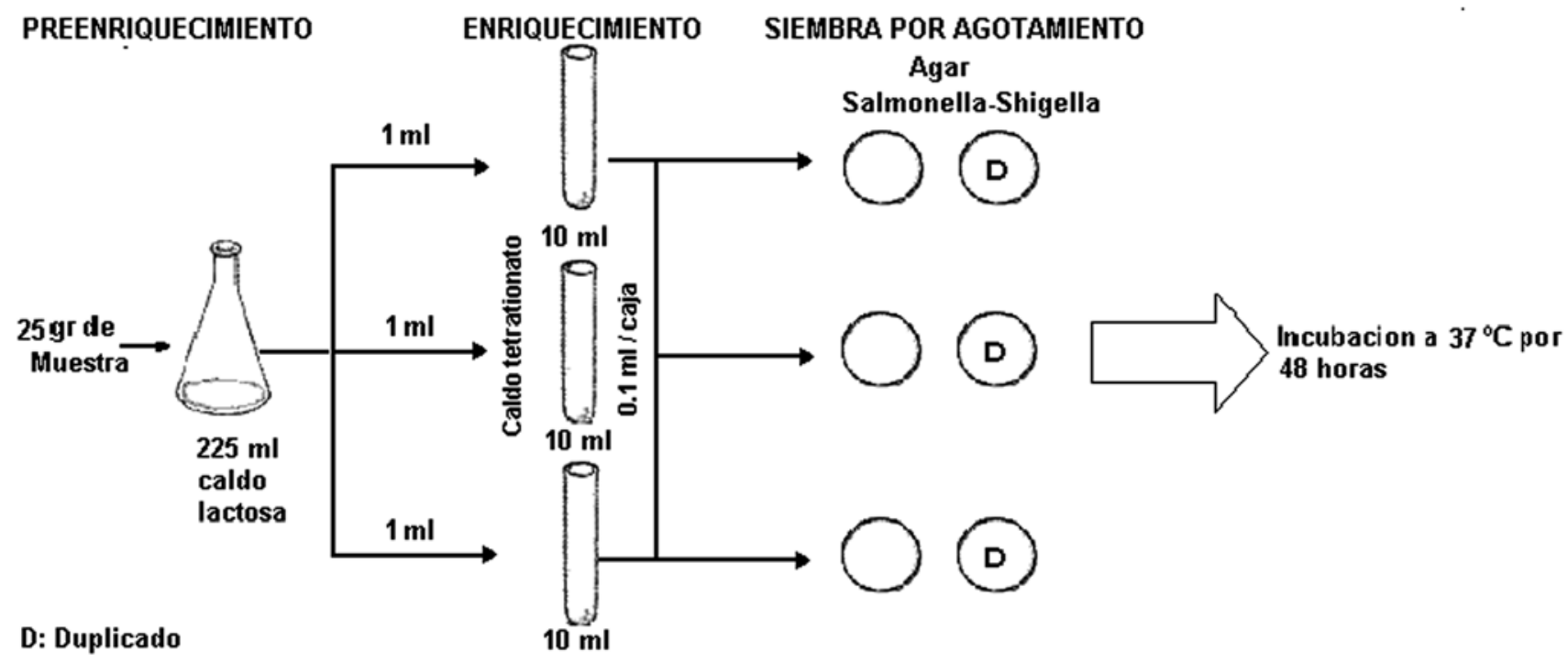

\section{RESULTADOS Y DISCUSIÓN}

\section{ENSAYO PRELIMINAR}

\section{Hongos fitopatógenos}

Las diluciones seleccionadas para el ensayo $\left(10^{-6}, 10^{-7}\right.$ y $10^{-8}$ ) fueron muy altas y por tal razón el aislamiento para identificación de hongos fitopatógenos no fue posible; sin embargo, este análisis preliminar permitió determinar que el rango de diluciones adecuado para el ensayo final debía ser de $10^{-3}, 10^{-4}$ y $10^{-5}$. Paralelo al estudio de identificación se realizó la evaluación del potencial agrícola de este compost en un cultivo de rábano, y no se presentó ninguna sintomatología de las enfermedades causadas por la presencia de hongos fitopatógenos [17].

\section{Salmonella sp}

En el análisis de presencia de Salmonella sp utilizando el medio selectivo agar Salmonella-Shigella (SS) se encontró que las colonias positivas fueron de fácil identificación en comparación con el medio agar bismuto sulfito, por lo tanto, se recomienda la utilización de agar SS para la siembra en agar selectivo. La presencia de Salmonella sp en el compost fue positiva, los resultados mostraron el crecimiento de colonias transparentes con el centro negro y las colonias incoloras en medio Agar SS.

\section{ENSAYO FINAL}

\section{Hongos fitopatógenos}

Los resultados mostraron que el único genero de patógenos detectado en el compost fue Fusarium sp, relacionado con enfermedades radiculares de muchas especies de plantas. En un estudio simultáneo de evaluación del potencial agrícola de este compost en rábano y acelga, se encontró que este hongo hace parte de los microorganismos nativos del suelo, por lo tanto, se recomienda realizar tanto la identificación como la cuantificación de estos microorganismos para lograr determinar el verdadero impacto en los cultivos [17].

Aunque el análisis de fitopatógenos mostró la presencia de Fusarium sp. en el compost y en el suelo no se observaron síntomas de enfermedad en las especies 
vegetales evaluadas lo que puede deberse a que las concentraciones del hongo presente en los tratamientos no son suficientes para presentar sintomatología [17].

\section{Salmonella sp.}

Del mismo modo que para el analisis de hongos fitopátogenos, las muestras de compost y suelo mostraron la presencia de Salmonella sp, indicando una posible contaminación. La presencia de este patógeno en el suelo indica que puede hacer parte de los microorganismos del mismo; sin embargo, sería recomendable realizar su cuantificación para definir en qué concentraciones puede llegar a convertirse en un problema de salud pública. El tiempo de sobrevivencia de Salmonella $s p$ en el suelo puede variar entre 15 a 280 días [4], este periodo debe tenerse en cuenta para la aplicación de un compost al suelo.

\section{CONCLUSIONES Y RECOMENDACIONES}

Las metodologías usadas para la determinación de hongos fitopatógenos y Salmonella sp. mostraron que las diluciones más adecuadas para el aislamiento de hongos fitopatógenos en las muestras de compost evaluadas fueron $10^{-3}, 10^{-4}, 10^{-5}$ y el medio más apropiado para la identificación de Salmonella sp fue el agar Salmonella-Shigella.

La identificación de hongos fitopatógenos mostró que de los cuatro géneros evaluados, el único presente fue el Fusarium sp; sin embargo, su presencia no causó enfermedades en la evaluación agrícola.

Se recomienda realizar la cuantificación de los hongos fitopatógenos presentes en un compost para definir en qué concentración el hongo pueden causar enfermedades que afecten los cultivos.
Se recomienda realizar estudios de fitopatogenicidad usando especies vegetales susceptibles a las enfermedades causadas por hongos fitopatógenos.

Se recomienda realizar tanto análisis de presencia como la cuantificación del patógeno Salmonella sp en el suelo para definir el tiempo de permanencia y la concentración en la que pueda llegar a convertirse en un problema de salud pública.

Se recomienda la higienización del compost producido con lodos de plantas de tratamientos de aguas residuales con el objetivo de reducir los potenciales riesgos a los cultivos y a la salud pública por el consumo de alimentos contaminados por este tipo de microorganismos.

\section{BIBLIOGRAFÍA}

[1]ALEMAN, Z.; MOLINA, I.; DIAZ, R.; RODRIGUEZ, M. (2003). Recobrado de Salmonella sp conservada por método simple a temperatura ambiente. Instituto nacional de higiene, epidemiología y microbiología. Cuba. 90pp

[2]BARBOZA, J.; AMES T.; JACOBSEN S.-E. (1999). Reducción de la germinación y muerte de plantas de chenopodium quinoa causadas por rhizoctonia y fusarium. Primer taller sobre quinua- recursos genéticos y sistemas de producción. UNALM. Perú. 131 pp

[3]COSTA, F; GARCÍA, C., HERNÁNDEZ, M.T. y POLO, A. (1991). Residuos orgánicos urbanos. Manejo y utilización. Consejo superior de investigaciones científicas-centro de edafología y biología aplicada del segura, Murcia. 100pp

[4]EPSTEIN E. (1978). Laud Disposal of Toxic Substances and Water Related Problems. Journal Water Pollution Control Federation; 50, 8. p. 2037 - 2042. 
[5]HOITINK, H. y GREBUS, M.E. (1995). Nurseries Find Special Values In Compost Products. Green Industry Composting (BioCycle). p. 26-27.

[6]MENDOÇA, S. (2000). Sistemas de lagunas de estabilización. Ed McGraw-Hill. 370pp

[7]METCALF \& EDDY. (2003). Waste engineering: treatment, and reuse. Fourth Edition Ed. Mc Graw Hill. $1819 p p$.

[8]MERCK. (1994). Manual de medios de cultivos. 688pp.

[9]MORALES, J. (2003). Infojardin. Plagas. Hongos. En www. Infojardin.com

[10]NORMA TÉCNICA COLOMBIANA NTC 5167. (2003). Productos para la industria agrícola y materiales usados como fertilizantes y acondicionadores ICONTEC. $39 \mathrm{pp}$

[1 1 ] PIEDRA, R. (2002). Control biológico en floricultura. Memoria del II Encuentro de investigadores en agricultura orgánica. Asociación de Productores de Flores de Llano Grande de Cartago. 2pp.

[12]ROMERO, L. (1982). El Compost como factor determinante para una mejor producción agraria. Boletín de Información del Medio Ambiente (BIMA). No. 2. Abril - Junio. 80pp.

[13]SILVA, J.A (2004). Evaluación de la fitopatogenicidad y potencial agrícola del compost producido con biosólido de la Planta de Tratamiento de Aguas Residuales de Cañaveralejo PTAR-C de Cali. Universidad Francisco de Paula Santander. Ingeniería de Producción Biotecnológica. 111 pp.

[14]REELEDER, R. (1995). Rhizoctonia Diseases of Ginseng. Ministry of agriculture and food Ontario. $5 \mathrm{pp}$
[15]TAYLOR y LEE. (1990). Protocolo de extracción de ADN de Phytophora vignae, Phytophora citricola y Sphaceloma manihoticola. 80pp

[16]TCHOBANOGLOUS, G.; THEISEN, H.; VIGIL, S. (1994). Gestión integral de residuos sólidos. Mc Graw Hill. Aravaca. Madrid. p 115-138, 755-804.

[1 7]TORRES, P; SILVA, J.; ESCOBAR, J. (2007). Potencial agrícola de compost producido con biosólidos de plantas de tratamiento de águas residuales. Revista Live Research for Rural Development. CIPAV. (sometido). $11 \mathrm{pp}$.

[18]TSUKAMOTO, Ricardo Y. (2002). Tratamiento Primario Avanzado: El Paradigma Moderno del Tratamiento de Aguas Residuales Sanitarias, $1^{a}$ Parte. En: Revista Agua Latinoamérica Vol. 2, No. 2. 4 pp.

[19]URIBE, I. (2005). Evaluación del compostaje de biosólidos de la PTAR-Cañaveralejo de Cali. Maestría en ingeniería sanitaria y ambiental. Universidad del Valle. 120pp

Recibido: 25 - Octubre - 2006

Aceptado: 17 - Mayo - 2007 